\title{
CULTURAS MARÍTIMAS Y RELACIONES DE PODER. LA TRAYECTORIA DEL MARISQUEO A PIE EN LAS RÍAS BAJAS GALLEGAS ${ }^{1}$.
}

\section{MARITIME CULTURES AND POWER RELATIONS. THE PATH OF THE SHELLFISH BY FOOT ON THE GALICIAN COAST (SPAIN)}

\author{
ESMERALDA BROULLÓN ACUÑA \\ Investigadora contratada del Centro de Ciencias Humanas y Sociales del CSIC
}

\begin{abstract}
Resumen
El siguiente artículo muestra la trayectoria del trabajo femenino desarrollado en un territorio de frontera como son las riberas marítimas del litoral noroeste de la Península Ibérica. Es el denominado "subsector" de las mariscadoras a pie de las rías bajas gallegas. A partir de un trabajo de campo en dicho entorno hemos analizado la segregación ocupacional en razón al género, al hilo de las condiciones en que tradicionalmente se desarrollaban dichas faenas. Mientras tanto las protagonistas narraron el itinerario recorrido por el colectivo femenino para la consolidación "profesional" del oficio de mariscadora.
\end{abstract}

\section{Palabras claves}

Intrahistoria y marisqueo, feminización del trabajo, ecofemininismo, culturas marítimas y relaciones de poder.

\begin{abstract}
The following article addresses a female labour developed in a frontier territory such as the maritime banks of the northwest coast of Spain which is the so-called "subsector" the gatherers walk from the Galician (Spain). Of a field in such work we have half analyzed occupational segregation because of gender in the thread of the conditions that traditionally developed these jobs, while the same protagonists hearings trajectory traveled by the collective female for the "professional" consolidation.
\end{abstract}

\section{Key words}

Intra tells the history and shellfish, feminine of the work, ecofeminism, cultures maritime and power relations.

${ }^{1}$ Recibido/Received 18.01.2010. Aceptado/Accepted 07.03.2010 


\section{FUNDAMENTACIÓN TEÓRICA Y EMPÍRICA DE LA FEMINIZACIÓN DEL TRABAJO: LA INTRAHISTORIA DEL OFICIO DE MARISCADORA}

En el siguiente artículo partimos de la categorización de la feminización del trabajo para revisar la histórica asignación en la esfera socio-laboral de unas determinadas adscripciones sexuales a hombres y mujeres. Hemos tenido en cuenta aquellos valores que previamente estereotipan el trabajo y en el medio marítimo las mujeres mantienen la ineludible tarea de la reproducción ${ }^{2}$, dimensión que pertenece al ámbito de lo doméstico junto con otras disposiciones extradomésticas en las fronteras de la cultura pesquera a las que pertenecen.

La separación del modelo analítico, producción y reproducción, fue planteada por Iris Young como un medio limitador de las posibilidades en que son presentadas las mujeres $^{3}$. Entre los primeros enfoques que nos remite al razonamiento analógico, producción-reproducción, lo encontramos en los presupuestos economicistas de la teoría engelsiana, al vincular el surgimiento de la propiedad privada y el desarrollo de la familia monógama con la opresión femenina, adquiriendo en este caso un protagonismo relevante el control de los medios de producción ${ }^{4}$. Es decir, éste proceder teórico se erige como uno de los antecedentes en la separación, por un lado del ámbito de la familia, lo doméstico, y por otro lado, el de la "pura" economía. O lo que es lo mismo, segmentando los espacios público y privado para hombres y mujeres se perpetúan dichos "dualismos". Si aplicamos estos presupuestos al ecosistema y nicho laboral marítimo podemos afirmar que en las sociedades pesqueras la división del tra-

${ }^{2}$ El proceso de reproducción aludido es el denominado por G. Rubin como "Sistema Sexual del Género". Véase, RUBIN, Gayle, "The Traffic in Women: notes on the <political economy $>$ of sex", en R. Reiter (comp.), Toward and anthropology of women, Monthly Review Press, Nueva York, 1975, pp. 157-210.

3 YOUNG, Iris, "Socialist feminism and the limits of dual system theory", Socialist Review, n 50-51, vol.10, 1980, pp. 169-188.

${ }^{4}$ ENGELS, Friedrich, Origen de la familia, la propiedad privada y el Estado, Madrid, Fundamentos, 1987. En contraposición al planteamiento engelsiano, C. Meillasoux centró su objeto de estudio en la "comunidad doméstica". El autor mantuvo la importancia del control de los medios de reproducción al subrayar el potencial reproductor de las mujeres, remitiéndonos a ello por la afinidad en torno al parentesco y al intercambio de mujeres, mecanismo que fomenta la interdependencia familiar y crea la sociedad. Para Meillasoux, desde la óptica de las relaciones sociales de reproducción, el eje central para el desarrollo social es por lo tanto la esfera doméstica. MEILLASOUX, Claude, Mujeres, graneros y capital, México, Siglo XXI, 1985. Para una crítica de las tesis de Meillasoux, véase, MOORE, Henrietta, Antropología y feminismo, Feminismos/Cátedra, Madrid, 1991, pp. 69-72.

5 En relación al espacio donde se desarrolla un determinado trabajo partimos de la propuesta de Michelle Rosaldo quien sostendría que el espacio en sí mismo no otorga poder y sí la actividad legitimada como masculina o femenina, en función a unos sistemas culturales que proporcionan autoridad y una mayor estimación social a las tareas masculinas. Véase, ROSALDO Michelle en, HERNES Olivia y YOUNG Kate (comp.), 1979, p. 155 
bajo en razón al género, representado en el par mar-hombre/tierra-mujer no solamente se corresponde con la limitación artificial del espacio público-privado, si no que esta es mucho más que una mera dimensión técnica. En realidad es una estructura discriminatoria retroalimentada por unas relaciones de dominio y subordinación.

A partir de un estudio de campo en una comunidad marítima como observadora participante podemos atestiguar que una concreta ideología subyace en la base de las desigualdades sociales que habitan entre los sexos. Ideología que radica en unas costumbres naturalizadas y definidas por una esencialidad masculina/femenina. En este terreno hemos proseguido los postulados teóricos de Anna Scoot, en torno a la correlación existente entre las instituciones y las consecuencias de una previa ideología familiar para la incorporación de los sujetos al mercado de forma segregacionista ${ }^{6}$. En términos de Scott el género cuenta y lo relevante de esto es la inclusión del componente de género al mercado laboral y la estereotipación ocupacional en razón al sexo. Sobre esta última cuestión continúa el nudo gordiano por el fuerte sesgo ideológico economicista del término "producción", donde además el trabajo -doméstico y familiar- femenino quedaría fuera del análisis y la contabilidad nacional, si bien entendemos que esto no ocurre en la praxis cotidiana. Así pues mediante esta práctica empírica tratamos de introducirnos por las fisuras de estas categorías estancas que tradicionalmente excluyen del mercado de trabajo aquello que no funciona como "pura mercancía".

A nivel empírico nos centramos en el trabajo femenino desarrollado en un territorio de frontera como son las riberas marítimas del litoral noroeste de la Península Ibérica, es decir presentaremos la trayectoria de vida del denominado "subsector" de las mariscadoras a pie de las rías bajas gallegas. Tras una primera observación en el terreno de campo sobre la segregación ocupacional en razón al género, comprobamos las condiciones en que tradicionalmente se desarrollaron dichas faenas. Asimismo explicitamos sus estrategias en la arena política para la consolidación "profesional" del oficio de mariscadora ${ }^{7}$, y como ejemplo tomamos el caso de

\footnotetext{
${ }^{6}$ SCOTT, Anna, 1986, pp.1053-75.

7 Enterrado o semienterrado en la arena, los recursos de las riberas marítimas -berberechos, almejas, ostras, etc.- han sido de manera tradicional extraídos a mano con escaso y rudimentario instrumental. Destinados para el autoconsumo, el comercio o la exportación, servían también de pago a rentas feudales. La larga coexistencia de esta región con el mar, además del deber al servicio obligatorio de los mareantes a la Armada desde el siglo XVII, los frecuentes naufragios, la escasa tecnología que hasta iniciado el siglo XX impedían realizar las labores pesqueras durante el invierno o el fenómeno de la emigración son todos ellos aspectos que aportan relevantes datos del lugar ocupado por las mujeres en la economía y la sociedad gallega. De este modo, una parte de su manutención y subsistencia dependían del trabajo realizado por ellas, siendo uno de los más comunes el de mariscadora.
} 
Moaña en Pontevedra (Galicia). El perfil, la dimensión social y simbólica, que las define es el de extractoras en las arenas de las playas, pues conocedoras del medio se consagran al lugar en el que viven: el de un conflictivo espacio físico y sociocultural. Un territorio que ha sido objeto de una explotación a raíz del consumo de marisco, revitalizado por el impulso de las modernas sociedades de consumo como mecanismo de distinción social ${ }^{8}$. La historia del marisqueo, inmersa en un hostil proceso, fue descrita en un escenario de contrariedades socio-políticas. El trabajo de las mujeres que tradicionalmente venían desarrollando estas faenas ha estado supeditado, en una retroalimentada relación, a la asignación de un estereotipo ${ }^{9}$. Al hilo de sus relatos de vida examinamos la historia de este antiguo oficio:

"Venia sobre todos mujeres coas fillas, irmáns y vendían en la calle lo recogido o pa casa. As campañas abríanse o primeiro de octubre e o catro ou cinco xa non había marisco na playa. Logo quedaban aquelas oito ou dez mulleres a coller ameixa, en venderlle aquelas persoas como era miña nai, unha intermediaria que eran as que facían os cartos. y miña nai cando iba a buscar a vida dicíame: cando veña... cóllelle o marisco (aínda parece que estou mirando pa ela). Si ven fulanita págalle a tanto, si ven menganita a tanto... ¡Eu eso! para min era tremendo e eu era unha nena que estaba solteira, eu discutía coa miña nai, dicíalle: ¿por qué ten que ser as mariscadoras diferentes? Ela dicíame: porque nin os dedos das mans son iguales, eu teño mais confianza con aquela que con aquela... ipero si o marisco é igual! ¿por qué non tes que medir a todo o mundo pola misma medida? Y eso eu era o que non soportaba e dicía: ¡si algún día son eu mariscadora... si algún día cando me case eu quero ser mariscadora, a min no me vai embarcar ni miña nai nin nadie! jeu quero que me paguen como lle paguen as demais!" 10.

En la memoria colectiva de la comunidad estudiada el marisqueo en las riberas marítimas se concibe como una vetusta práctica, de manera que las orillas han sido históricamente explotadas por una multitud de grupos domésticos que, mayoritaria-

8 BOURDIEU, Pierre, La distinción. Criterios y bases sociales del gusto, Madrid, Taurus, 1988; VEBLEN, Thorstein, Teoría de la clase ociosa, México, FCE, 1944 (1899).

9 Sobre la legitimidad/ilegitimidad de los estereotipos relativos a los trabajos femeninos véase los ejemplos expuestos en BAYO, Eliseo, Trabajos duros de mujeres, Barcelona, Plaza Janés, 1970. En esta obra se describen oficios realizados exclusivamente por mujeres bajo unas duras condiciones, como el de las mariscadoras de las rías bajas gallegas o las jornaleras andaluzas.

10 Mujer, 60 años. Moaña. Pontevedra, diciembre del 2007. 
mente, buscaban un ingreso adicional a la siempre desigual campaña o marea realizada por el hombre, esposo o padre en el mar ${ }^{11}$. Durante un corto periodo de tiempo, apenas unos días, las orillas eran tradicionalmente trabajadas por una abundante mano de obra que informalmente se dedicaba a la labor puramente extractiva. En consecuencia la presión de dicha mano de obra ejercida sobre un mismo recurso producía un efecto benefactor para los intermediarios, en especial para los vinculados a la industria conservera. $Y$ de este modo, las condiciones en que se desarrollaba, año tras año, esta labor extractiva llevaba a estos últimos agentes sociales a controlar la producción bajo sus propios intereses, argumentando que se trataba de un recurso obtenido a través de unos medios y empleos "no especializados", reproduciendo en consecuencia un trabajo "depreciado" que favorecía ventajosamente a los compradores:

"E había outra cosa, por ejemplo, abrías a campaña a primeiro de octubre e esa playa estaba sempre chea de berberecho, e os fabricantes poñíanse dacordo y en vez de dicir: ¡bueno! esta xente están embargadas, cousa mais, cousa menos ¡A min y a outra, non a min, non, cómprame a min..., lévame a min (risas)! Y eles collían y marchábanse.... ¡Non, hasta mais tarde non collemos!. Y poñíanse dacordo no prezo y poñíalle aquela y alí había quinientas mulleres, iporque íbamos tres ou catro mil a cada playa. Sí, sobre os anos sesenta, sin carné, sin nada e o mellor votabas co saco na cabeza de trinta ou corenta kilos e cincuenta, pingando o mellor tres ou catro horas alí, e chegabas a cola y o mellor a que estaba encima do camión. Porque eu xa non me acordo pero aquelo teño moi ben gardado, 'tze,tze' (chascarrillo, lamento). Chegabas alí y dicíante: ¡ti, ti, pasa ti' y a outra contestaba, ¡estaba eu antes! Bueno era tal esclavitud. Y todo iso, despois de facer unha organización como a que fixéramos, porque non éramos capaces de quitar eses intermediarios que nos trataban asî". ${ }^{12}$

A pesar del carácter subsidiario que a lo largo del tiempo caracterizó al marisqueo a pie, éste es un claro ejemplo de su aportación como actividad productiva a las economías pesqueras, siendo a su vez objeto de conflictividad en el acceso, uso y explotación del mismo. Pero esta dimensión, entendida a priori, como comple-

11 El marisqueo a pie ha estado estrechamente vinculado a la pluralidad de bases económicas de las sociedades pesqueras, aunque con un carácter desigual. Percibido como una actividad económica marginal de todo aquel que vivía cerca de la mar, ha sido tradicionalmente detentada por la colectividad de mujeres vinculadas a familias de marineros en busca de recursos básicos para la subsistencia y el autoconsumo.

12 Mujer, 60 años. Moaña. Pontevedra, diciembre del 2007. 
mentaria ${ }^{13}$, no hizo más que reproducir la condición social de las mujeres, las cuales seguían ocupándose básicamente de "la casa":

"Pero traballamos muito porque non querían, non quería nadie que as mariscadoras tuvesen seguros porque decían que o marisqueo era 'complementario', por si unhas mulleres querían comprar unhas bragas o una típica axuda. Eu non quero que sea unha axuda, eu quero que sea o meu traballo. Nos, nestes momentos estamos invirtindo muitos cartos nas playas. As mariscadoras invertimos porque ahora estamos ganando y para ganar cartos hay que invertir, como calquer empresa" 14 .

Por consiguiente observamos una doble discriminación, reforzada por su propia cultura de género, que como esposas de hombres de mar ocupan una determinada posición, incidiendo de manera negativa esta condición subsidiada, por carecer de recursos personales propios y por tener un nivel sociocultural precario que las alejaba tanto de la participación de las estructuras organizativas locales como de las redes comerciales a las cuales estaban subordinadas. Todo ello favoreció el hecho de identificarse, hasta hace muy poco tiempo, como amas de casa en lugar de mariscadoras propiamente dichas ${ }^{15}$. Esta autovaloración, reforzada por los meca-

13 Este proceder ideológico nos remite a la constitución del salario familiar, entendido como un hecho central en la historia del obrerismo de mediados del siglo XIX y principios del siglo XX. Su consolidación como tal facilitó la legitimación de unos salarios complementarios a las trabajadoras. Bajo esta ideología, el trabajo femenino fue apartándose del mercado, constituyendo en una práctica operativa para el capital. Es decir, al otorgar a un sistema productivo la inclusión de un salario familiar sirvió de fundamento para legitimar la idea de "ayuda" aportada por las mujeres. La aparición del salario familiar, sostiene Celia Amorós, fue posible por la existencia de lo que denomina la filósofa como "pacto patriarcal interclasista". Véase AMORÓS, Celia ,1992. En una misma línea Anna Jónnasdóttir, en su crítica a Heidi Hartmann, entiende este sistema -el patriarcado- como la "alianza de los hombres por encima de las fronteras de clase". Cfr. Anna JÓNNASDÓTTIR: 1993, p. 86. La realidad descrita en las autobiografías y observada durante el trabajo de campo prioriza la figura del "proveedor principal", papel consolidado en el esposo. Mientras tanto, entendemos que este proceder favorece la institucionalización del control masculino.

14 Mujer, 60 años. Moaña. Pontevedra, diciembre del 2007.

15 En los estudios realizados sobre el marisqueo a pie, al preguntar a las mujeres sobre su cultura e identidad profesional éstas siempre respondían, a pesar de tener el carné como mariscadora, ser "amas de casa”. Acerca del significado de esta cuestión véase, SEQUEIROS, José Luis (dir.), A despensa de area, Xerais, Vigo, 1995; BEIRÁS, Xosé Ramón, (dir.), Posibilidades y limitaciones económico ecológicas del polo de desarrollo de Vilagarcía de Arousa: estudio del sector marisqueo en la Ría de Arousa, 1976; PARDELLAS DE BLAS, Xulio, "El trabajo de la mujer en la pesca y el marisqueo en Galicia”, en VV.AA., Jornadas sobre Economía y Sociedad de las Comunidades Pesqueras, MAPA y Universidad de Santiago, Madrid, 1989, pp.431-38; MARUGÁN PINTOS, Begoña, Y cogieron ese tren. Profesionalización de las mariscadoras gallegas, Consellería de Pesca e Asuntos Marítimos, Xunta de Galicia, 2004. 
nismos externos, las recluían a un territorio del que difícilmente podrían salir. El discurso de una de las agentes sociales perteneciente a esta cultura productiva marítima -segmentada y estigmatizada en razón al género-, fue revelador para el estudio de la división sexual del trabajo en dichas sociedades:

"Nos tíñamos unha reunión sempre, por ejemplo, sobre o vinte de setembre y era no mes que pedía a los da directiva que: ¡a ver si non facedes burla das mariscadoras, aínda que non o paguedes caro, pero quítenllo da cabeza. Había un señor, chamábase (...) y nunha reunión sentada nunha mesa muy grande que ten a cofradía de Moaña, pois o patrón de turno, dese momento y eu, na reunión pedín de favor (solo me faltaba poñerme de rodillas), a pedirlle que non se portaran tan mal coas mariscadoras. Entón ese señor, que era bastante pequeno, levántase, levaba un anillo moi grande, levántase y así como se levanta, fai así coa chaqueta de coiro, levántase, fai así pra atrás y trae unha pistola... Por iso eu teño no recordo y había alí como treinta compradores alí a o redor, foi nos ochenta y tanto xa, porque nós levábamos moitos anos indo pero era unha campaña tan traballada, con tanto marisco... pero os prezos votábante abaixo os compradores. Non me faltaba mais que poñerme de rodillas y él se levanta y di a os outros: ¿Vos estades oíndo a esta muller? Pero... ¿pero moza, ti de dónde ves? ¡Já! Votou a rirse de min. Non, eu non lle pido nada, no máis lles pido que non fagan burla das mariscadoras. ¡Bueno, bueno, vámonos da aquí home, vámonos da aquí! E marcharon... e fomos a mariscar, pasou... E o primeiro día xuntábanos a directiva que éramos socias e dixemos: Bueno, hasta aquí chegamos... Ou isto poñémolo andar ou e mellor que o deixemos porque estamos pintando o parvo. Eles traballan tres ou catro días, os compradores e non traballan en todo o ano. porque o mellor facías douscentos ou douscentos cincuenta ou sesenta mil kilos, por tres ou catro días de marisqueo, solamente de berberecho, ahora o resto... Entón eles eran os amos, os intermediarios" 16 .

Frente al contradictorio proceso del marisqueo "tradicional" en el que se ven inmersas, así como ante el rechazo de sus demandas más básicas, éstas se enfrentaron al dominio de quienes se apoyaban en su histórica marginalidad. La protagonista de este relato describe las estrategias diseñadas por el colectivo femenino que

16 Mujer, 60 años. Moaña. Pontevedra, diciembre del 2007. 
consideramos relevante debido a las prácticas de resistencia desplegadas por parte de las mismas:

“Entón aquel día... 'hasta aquí chegamos'. Bueno, vamos a facer unha cousa que é un pouco arriesgada, porque nos tocamos canto fabricante había, éche decían todos: No, no, nos xa temos nosos intermediarios. Nos, cando se abría a veda, eles viñan un mes antes a levar mostras, incluso se reían do que levaban, porque pedían unha mostra para unha fábrica, con tres ou catro kilos. E o mellor ti sabías que estaban comendo nos bares cos amigos. Y nos: ¡para o ano as mostras se acabaron e vamos arriesgarnos! Ningunha quería, todas éramos mulleres, ¿pero estás loca? Vámonos a poñer a recoller o marisco a xente, vámolos a seleccionar, vámonos a poñer trinta ou cuarenta mulleres selecciónalo e con báscula y vámolo a subastar. ¡Bueno! A que mais ou a que menos, ¿estás loca, estás loca? ¡Despois quédannos! ¡Que son capaces de xuntarse todos. E mellor que nos mate a xente que estar o que estamos facendo, porque levamos un montón de anos traballando para estes señores... Eu xa non me importa que en vez de pagarllo a cen pesetas o paguen a cincuenta. Entonces sobre o seis ou sete de setembre, eu xa lle dixen a elas que isto vai a ser un secreto entre nos, eu non quero nin que se comente na casa porque si se comenta na casa pódelle chegar os compradores y vaise a pinchar todo. Todo iso un ano antes y un ano de traballo. Entón o patrón maior di: mira os compradores están a pedir unha reunión. Pues dí que este ano non hai mostras que este ano hai pouco. E a pedir unha reunión: Non, vamos a facer a reunión dous días antes. ¡Hombre que ten que mandar pedir os camións! Porque viña unha flota de camións tremendos alquilados. ¡Bueno, pois nós hasta dos días antes non a facemos!. Eu cheguei a cofradía, as miñas compañeira xa non quisieron ir, eu sola, chegou alí... o patrón maior: pero mira, ¿cómo fixéchedes a reunión tan tarde? E díxenlle eu: Porque cambiou este ano, vámolo a subastar nos. O señor era alto, moi alto... ¡encogió! ¿Qué me estás dicindo? Este ano vámolo a subastar nós, vamos a poñer en montes, seleccionalo o berberecho, porque esta playa sempre o tuvo moi bo (ahora cos aterrados pero antes). ¡Eh! e vamos a subastálo nós ¿Estades locas? pois estaremos... (subastálo o subastaba a cofradía). Nos podíamos facer pero non tíñamos quen no lo collera, tocamos a toda canta porta. Ahora, ahora e outra norma, por ejemplo como ti por cofradía pertenécete un cupo, podes vendélo a lonxa, a lonxa que queiras. ¿Ti sabes o que estades facendo? Al salir: ¡A ver que vos estábamos esperando, canto e que tiñámos os camións 
contratados! Díxenlle eu: bueno, pois estades todavía a tempo porque pasado mañan o berberecho vai todo a subasta' (largo silencio). Po isto foi ochenta y algo. ¡Eh! ¿non nos pudéchedes avisar? Non fai falta, vos vades a subasta e o que mais pague e o que o vai a levar. ¡Bueno! Eu levaba como oito días de descomposición, porque na miña casa non sabían nada, meu marido e marino mercante e non estaba, eu teño catro fillos, un a traballar outros a estudiar, eu estaba. ¡Porque nos temos un prezo de fábrica! decían. Y nos: bueno pois traedes os fabricantes e o que mellor o pague é o que o vai a levar"17.

Los efectos de este simulacro sirvieron para exhortar a las mujeres a que fueran ellas quienes obtuvieran beneficios de su trabajo. Mientras tanto, la leyenda conflictiva de la cultura productiva del marisqueo a pie era reforzada por los medios de comunicación ${ }^{18}$ :

"Coa misma, empezamos a traballar o primeiro día, viñeron os periodistas todos, querían gravar, era o único que facían. Porque 'a guerra' viñan, viñan a gravar as guerras... incluso hay encuestas que eu falo despois de todo iso e digo: o único que se conoceu das mariscadoras de Galicia era polos líos. Y ahora a facernos unhas encuestas para salir en libros que é o que queremos, que nos conozcan polo noso traballo non polos líos... Bueno pois eu falo cun da cofradía que era un do Cabildo, ¿Lolo mañan podes vir a subastar? ¿Subastar cómo? Pois pasa isto e isto...Tí sabes con tres ou catro mil personas, con todo o berberecho e despois moitísimo de ameixa, a babosa e todo e a subastála, ti sabes os montes tan grandes...Pero aquí había que facer algo porque levamos tantos anos traballando pra ista xente e a xente daite pena mirala. Ahora... ¿quén colle a primeira pedrada? (risas)... Fixemos uns pasillos con cordas, os montes grandes, bolsas... Viña unha mariscadora, votaba as caixas cunha letra con cada tipo, tales kilos... As cinco da tarde empeza a subasta pero xa con muita menos xente. Coa misma, poñémosnos encima do monte de berberechos, o home ese mais eu: ¡Lolo, pésame isto! Cando chegou a un precio, mais ou menos, un pouquiño que o ano anterior que pagaran eles...

17 Ídem

18 La estigmatización del oficio de mariscadora está patente y legitimado con su presencia casi a diario en los medios de comunicación visual y prensa escrita durante los años 1998 y 2000. Este es un aspecto a tener en cuenta en la reproducción de su condición social. 
¡Lolo para! vamos a outro. Había douscentos cincuenta ou douscentos sesenta mil kilos en terra, nuns montóns enormes. ¡Vamos a outro monte, vamos a outro monte, ta, ta ,ta! Cando chegou ao precio mais ou menos...¡Para Lolo! este tamén está. Así que vamos o tercer monte, oio: ¡mío!, ¡mío! Vamos a outro: ¡mío! Outro: ¡mío!. Logo ven un vendedor da aquí que se chama... y: ¿para quen é estes dous de aquí? Mira, esta vendido, se quérelo ti, lévalo ti pero o prezo que foi, pero porque estabades aquí, si non iba todo. Mira hoxe nadie sabe... despois súpose, sí, sí, que fomos nos as que parábamos aquilo. Y desde ese ano hasta hoxe pero foi un riesgo tremendo porque... foi un engaño, foi un engaño... pero víñaslle moi ben. Ti sabes o que era nos por as carreteras, o berberecho tirado... que si o compraban aquela, aquela, a outra, non, non. ¡Non meu quiso! vou levalo para comer o resto a tirar con el..."19

Sólo las prácticas de resistencia descritas por este colectivo, representado por mujeres que venían realizando durante generaciones unas faenas "tradicionales", vinculadas a un espacio tan disputado como es el de las riberas de las playas, consiguieron derrocar un consolidado poder detentado por varones ${ }^{20}$. Así lo pudimos comprobar en otro de los sucesos relatados, en este caso un conflicto supeditado al dominio de la masculinidad por el control de las Cofradías marítimas:

"Os mariñeiros aquí van individualmente.Y eles ... ¡non, non, non queremos que veña ningunha muller! ¡Vale! Entón eu me levantei y xa en esta reunión... non teño máis que falar. Entonces o luns fomos a Consellería de Pesca e veu o Secretario General de Pesca no sábado seguinte. E ao sábado seguinte estábamos na reunión y preguntou o Secretario ao Secretario da Cofradía, ¿cantas socias somos? Nese momento éramos trescentas setenta e tres en el dos mil y entonces pregunta o secretario si todas éramos socias. Y pregunta cantas somos: 'tantas', y ¿cantos mariñeiros? 'tantos', y... ¿cantos armadores? 'tantos'. Porque os mariñeiros van como traballadores que é como estamos nos y despois hai

19 Mujer, 60 años. Moaña. Pontevedra, diciembre del 2007.

${ }^{20}$ En el abordaje de esta línea de actuación hemos seguido el proceder teórico acerca de la articulación entre patriarcado y capitalismo así como su vinculación con la división del trabajo en razón al género, desde donde se construye el inferior estatus femenino. Véase, HARTMAN, Heidi, "Capitalism, Patriarchy and Job Segregation by Sex" en, Zillah R. Eisenstein, Capitalism, Patriarchy and the case form socialist feminism, London, Monthly Review Press, 1979 (Publicado originalmente como suplemento de Sings, 1 (3), 1976, parte 2) 
armadores que van como empresarios. Bueno... perténcenvos dez e os mariñeiros dous, entón eses señores dixeron, ¡diso nada! Bueno pois non teñen mais ustedes qué buscar a legislación.Pois vamos a denunciar, pois denúncieme donde queira. Pero era porque levaba muitos anos poñéndome o día en todo, eu que non sabía, sentábame cunha persoa que sabía y claro... eu sou unha persoa cunha edad muy avanzada y con moi poucos estudio, co certificado de escolaridad (...). A edad das mariscadoras, bueno ahora hai desde trinta e cinco anos pero a maioría son de cincuenta y cinco anos. Entonces bueno colleume dunha edad... Entonces bueno ahí buscamos o noso y o final un deles dixo: bueno pois como ustedes sodes catro, que os parece si... Nin cinco, nin catro, nin unha... o que nos pertenece. Ahora nin cinco, nin catro, nin unha, que nos pertenece dez, pois dez. Y ahí estamos dez. Pero é porque non se pode ser egoísta. Nos non decíamos nin cinco, nin catro nin unha, sino que facíamos unha candidatura conxunta y ahora eles... que sirve unha, catro, tres... bueno pois xa está, nos con tal de ter unha representación". ${ }^{21}$

El relato de las experiencias de las mariscadoras en las rías bajas gallegas, nos lleva a ser cautos al analizar su actual profesionalidad. La presencia de éstas, como agentes principales y benefactoras de los recursos del mar, ha originado serios enfrentamientos, reproduciendo a su vez el estigma social por el que se les impide enaltecer su tradicional trabajo:

"El mar es de todos y no hay derecho a cerrarle las puertas, porque hoy en día un pobre no puede ir a la mar, ni puede ir a la ribera. Los pueblos que tenían mar no pasaron hambre como los de interior.Todo el mundo tenía que comer porque cogían una liña e iban para el muelle a coger pescados, traían pescado ¿Qué las mariscadoras siembran la mar ellas? Sembraran la mar pero el terreno no es de ellas, el terreno está ahí y es de todos, eso es lo que no veo bien. Porque si yo quiero sembrar un campo de patatas tengo que tener el terreno si no a mi no me dejan echar las patatas en un campo que no sea mío. No estoy de acuerdo que se pueda esquilmar no, porque en la mar se podían poner unos topes de decir: 'bueno este pescado cuando desova, la almeja, el marisco, bueno unos meses... pero no que no se deje coger nada más que aquellas personas. $\mathrm{O}$

${ }^{21}$ Mujer, 60 años. Moaña. Pontevedra. Diciembre del 2007. 
sea unas familias pueden comer y vivir a cuenta del marisco y los demás no, los demás no; los demás si lo quieren lo tienen que pagar, yo no lo veo bien. Está todo cerrado... las mariscadoras ahora dicen que siembran la playa... yo no digo que siembren algo, ;ahora que se hicieran dueñas de la playa! Habrá un día en que no pueda ir uno a la mar. ¿En Moaña? aquellas son unas fieras". 22

\section{CAMBIO SOCIAL Y PODER EN LAS RIBERAS MARÍTIMAS}

A partir de los planes de explotación, puestos en marcha por la administración con fines de la regularización, gestión y ordenación de los recursos, así como en el desarrollo de unas normativas a favor de la "modernización del subsector", quedaron delimitadas las faenas del marisqueo ${ }^{23}$. Se trataba de domesticar a un colectivo que ya había dado muestras de un alto índice de "conflictividad", con antecedentes de enfrentamientos debidos al dominio de los hombres en el espacio de la cofradía y a las redes de comercialización. A cambio se estimuló su "coparticipación”, atendiendo a las experiencias de todas aquellas que faenaban desde tiempo atrás en las

22 Mujer, 60 años. Cangas, Pontevedra. Diciembre del 2007. La informante hace extensible su negativa a la restricción tanto del marisqueo a pie como del marisqueo a flote adscrito prioritariamente a los varones.

23 A partir de la Ley de 1961 de Explotación Marisquera de Galicia, se regulaba el dominio de las playas a favor del Estado, encomendando a las Cofradías el derecho a titular las concesiones para la explotación marisquera y conformándose en el interior de cada Cofradía los distintos oficios, entre ellos el de mariscador/a a pie y a flote. Otro de los momentos claves se alcanzó con la aprobación de la Ley de Ordenación Marisquera y de Cultivos Marinos de Galicia de 1985, que regulaba la condición de mariscador a partir del Decreto 116/87 y la Orden de 15 de julio de 1987, por la que se concedió la obtención del "carné de mariscador", decretándose la primera normativa autonómica en torno a la profesionalización. Otro hito logrado fue en 1993, con la Ley de Pesca (Ley 6/1993, del 11 de mayo) para la regularización del sector donde se contemplaba un mayor protagonismo, mediante mecanismos de control interno y externo, de las cofradías. La participación representativa en dicho ámbito está tradicionalmente detentada por varones, acusándose además un desprestigio y una infravaloración del oficio del marisqueo a pie (desarrollado por mujeres). Un sesgo reproducido históricamente por una limitada remuneración en razón a un "colectivo desacreditado" (el femenino) por el poder de los medios de información que han legitimado determinadas etiquetas sociales. En 1994 aparece el permex, mediante la Orden de abril de 1994, por el que se regula la obtención de permisos de explotación para dicha actividad. En 1997 se implanta el "Plan Diez", entendiendo el "marisqueo a pie" como una actividad extractiva en cuanto a su cultivo actual, y consolidándose la profesionalización de esta actividad en mano de mujeres, quienes logran hacerse presente con voz y voto en el seno de las masculinizadas Cofradías. Este es grosso modo el marco legislativo que enmarca el contexto y la trayectoria descrita por las fuentes orales. 
orillas de las playas, "con agua hasta la cintura". Este entramado favoreció a la profesionalización del marisqueo a pie $^{24}$, y de este modo las mujeres que ya laboraban en un territorio de frontera, como son las riberas de las rías, fueron incitadas a reformar -modernizar- su vernáculo saber. Para ello recibieron cursos de formación por parte de técnicos expertos en empresas pesqueras. Esto les condujo a un profundo cambio al ver transformado su rol laboral subalterno, lo que fue variando el carácter subsidiario y de ayuda familiar, al mismo tiempo que se implementó una monitorizada gestión sociopolítica centrada en programas formativos promovidos e impulsados para una mayor supervisión y control social ${ }^{25}$ :

"Hubo cofradías que non querían ni un curso e nos chegamos a dar trinta cursos. Empezamos polo de inserción, comercialización, dirección, do Plan de explotación de pesca... Nos fixemos cursos hasta para cómo facer unha reunión, cómo preguntar porque todas éramos amas de casa, pouco mais ou menos que leer, pero é que estábamos que éramos unha xente que estábamos mal. Porque nos temos unha asociación independente da Cofradía. Nos temos un diñeiro que está a nombre das mariscadoras, porque si o poñemos o nombre da Cofradía... pois é de todos y el riesgo é maior. Asociación hai trinta anos que está feita, unha asociación das mariscadoras, donde nos temos un reglamento y a Cofradía non pode entrar" 26.

Otro de los aspectos de la profesionalización como mariscadoras que produjo una fuerte confrontación social fue la afiliación a la Seguridad Social ${ }^{27}$, tratando

\footnotetext{
${ }^{24}$ Para una recesión acerca de la cronología legislativa y de las acciones socio-políticas claves, a partir de las cuales se encuadran y se desarrollaron la nueva realidad del marisqueo gallego en el contexto descrito, entendemos nosotros de la mundialización, en MARUGÁN PINTOS, Begoña, $Y$ colleron, pp. 297-99.

${ }^{25}$ Hemos tratado de abordar, en el marco de los relatos y experiencias mostradas, la actividad del marisqueo a pie más allá de la mera extracción, alternando su desarrollo a partir de la producción, el cultivo y la comercialización del recurso en cuestión. Ahora bien, los cambios acontecidos debemos enmarcarlos dentro del desempleo como un "negocio cultural" por el despliegue de cursos formativos que ha generado esta última forma de combatir la precariedad, además de ser un dispositivo de control social. La administración autonómica como gestora de los recursos y el territorio marítimo contaría, bajo este nuevo criterio, con fondos europeos para "combatir la discriminación laboral y segregación sexual" en dicho ámbito. Un proceso completado con la supervisión y el seguimiento de distintas fuerzas y "agentes expertos".

26 Mujer, 60 años. Moaña, Pontevedra. Diciembre del 2007.

27 Para una revisión de la situación de partida, las contradicciones y los beneficios de la afiliación véase, MARUGÁN PINTOS, Begoña, Y colleron, pp. 162-87.
} 
con ello de limitar la actividad asociada a una serie de derechos y obligaciones, a la vez que excluía de las riberas a aquellos/as que no optaron por el marisqueo a pie bajo las nuevas condiciones socio-laborales expuestas ${ }^{28}$ :

"Porque a Conselleira que hay ahora mismo de Pesca foi unha luchadora porque non hubera Seguridad Social pra as mulleres. Es unha nova, unha nova que non ten estudios, nin carreira pero tanto me da que non tuvera... pero que tuvera pero que supera. Porque ela formou unha asociación de mariscadoras a pé en Galicia, fai seis ou sete anos, pero é que non leva nada, nin si queres cultivar...Y ela decía que o 'seguro' que non tiña que ter as mariscadoras o seguro, porque o oficio das mariscadoras era un oficio mui antiguo pa que todo o mundo fora a mariscar si quería". ${ }^{29}$

Además de la compleja red tejida por distintos agentes para el dominio del recurso, la intrahistoria del marisqueo a pie del colectivo de Moaña (Pontevedra) revela la larga trayectoria de invisibilidad y marginalidad, así como el conflicto de la actividad artesanal y su desvaforecedora atomización. Este proceder fue trascendido cuando la dimensión extractiva del marisqueo se amplió bajo su propio sistema de producción. Introducidas en una nueva fase capitalizada la actividad mariscadora asiste a un cambio al centrarse ya no sólo en la extracción del recurso, sino que bajo el símil de "sembrar la tierra para obtener frutos", se pasa a concebir una nueva la labor de siembra y cultivo ante el principio de "adaptación al mercado". El nuevo proceso de trabajo implicó una transformación con respecto a la anterior labor y sus exiguas rentas ${ }^{30}$. En consecuencia, la informante sostuvo la siguiente posición ante la propuesta "cultivadora":

"Bueno iso fue que unha xente que estaba na Xunta pois dixo: empezar a cultivar, porque se queremos traballar todo o ano non é igual o que a naturaleza dá a que lle se arrime algo... En unha parte da praia, depende

${ }^{28}$ El proceso de inclusión/exclusión bajo la cobertura de la Seguridad Social coincide con el peor periodo para el sector del marisqueo a pie.

${ }^{29}$ Mujer, 60 años. Moaña, Pontevedra. Diciembre del 2005.

${ }^{30}$ Sobre el cambio social en el sistema de producción del marisqueo a pie en Galicia véase, SEQUEIROS, J.L., (dir)., op.cit., 1995; GAGO CONDE, Constantino y Ardora Formación: "La mujer en la pesca en Galicia", presentación de la investigación realizada para la Xunta de Galicia en el Simposio, "La mujer en la pesca, la acuicultura y el marisqueo en el contexto comunitario", Xunta de Galicia, Universidad de La Laguna y Red Europea FEMMES, 4-6 de febrero del 2004; MARUGÁN PINTOS, Begoña, Y colleron, 2004. 
das especies, compramos deses fondos que temos as mariscadoras y 'as mariscadoras deciden' pois si queremos cultivar esta clase de ameixa, da outra, a outra... y así podemos traballar todo o ano. Temos dous meses de paro biológico, que de momento non son remunerados pero esperemos que cos anos vaian a facelo, porque si os dan para os mariñeiros tamén nos vámolo a pedir. Nos sempre collemos de mediados de abril a mediados de junio, para ter o veranito... pois empezaron a vir ameixa de 'hacher' ${ }^{31}$, de semilla de desove, unhas plantas de fábricas, hai muitos anos que as hai, aquí non as hai muitos anos pero iso ten un problema que non hai 'hacheres' suficiente. É unha planta donde pos a ameixa a desovar y ten que haber unha parte técnica e nos... En principio nos non queríamos dentro o que era as praias que eran da ría de Vigo a ameixa japonesa, non e japonesa que e Italiana, italiana, francesa, pero bueno o mercado manda, o mercado manda e hoxe en día todo o mundo quere comer, e nos temos unha ameixa dun poder adquisitivo moi alto, entonces a babosa que e ameixa fina, nunca baixa de vinte oito ou trinta euros. En navidades estuvo en sesenta, setenta, non é para todos os bolsillos. As mariscadoras, sentámonos coa cofradía y en función dos muestreos que hai nas playas de un ano pa outro, en función que hay na playa pues... Entonces si collemos un supoñer cinco kilos diarios de ameixa babosa, podemos sacar cinco kilos diarios ou hacia abaixo, si nos por ejemplo ven un mes como ahora, un mes de enero, febreiro, son meses de mala venta, entón nos decimos, bueno pois en vez de quitar cinco kilos quitamos tres diarios. E cando hai venta quitamos os cinco, porque si quitamos o cupo que temos, que é un cupo bastante alto pois quitalo diario, ¿pra qué? Non hai venta... entonces en funcións das ventas, de que sea mais caro mais barato é como traballamos, chegamos a playa e... E xa temos un horario cada día pra entrar". 32

La realidad socio-política del marisqueo a pie es aún más compleja, no obstante tras este contrariado proceso por el dominio de las playas y de sus recursos, las mariscadoras obtuvieron una profesionalización con rentas más cuantificables. Por consiguiente los resultados de sus faenas en las riberas se incorporaron, por primera vez, a las estadísticas de la macroeconomía, abandonando la

${ }^{31}$ Hatchery, referido al sistema y estación de cultivo marino de la producción de semillas para el desarrollo de un sistema controlado.

32 Mujer, 60 años. Moaña, Pontevedra. Diciembre del 2007. 
anterior "cuasi-profesión" o actividad marginal, tal como venía considerándose, para integrarse por el contrario su sistema productivo al engranaje de la tecnocracia estatal:

"Nos somos autónomas, temos a seguridad social subvencionado polo Estado, como o mariñeiro que tamén a ten. Custounos traballo conseguilo y estamos como cultivadores y tamén non pagamos IVA, o contrario dannos o sete por cen como cultivadoras que tamén custounos traballo conseguilo y quen anduvo creo mais que foi a cofradía de Moaña, as mariscadoras de Moaña que lucharon por todas estas cousas porque fomos as primeiras en empezar, a ter o seguro, a ter o outro y entón... fomos as pioneras en todo ese traballo (sonrisa) pero bueno hoxe non hai quen este contenta coa seguridad social, porque foi o mellor que nos podo vir, foi o mellor porque estás enferma, tes unha baixa, retíraste e tes un retiro, tes y de outra maneira tes que depender sempre do home, do retiro do home. E bueno eu estou encantada de traballar y non ter a pensión de meu home, eu por ejemplo, eu sempre tuven a mía independencia"33.

Sin embargo la nueva cualificación del oficio de mariscadora, organizada en el sistema técnico en que se inserta su nueva empresa, precisará para su reproducción de nuevas imposiciones y concesiones. En consecuencia, se las requiere para realizar diferentes incursiones en el medio marítimo, al introducir y sobreestimular desde la administración y el mercado, una especie foránea que frente a la autóctona divide a la comunidad, tal como expresan los siguientes testimonios:

Biólogo 1": "El problema con el marisco y lo de aquí es que se quiere hacer de las playas un Benidorm, entonces tú para que se explotase de forma un poco racional las playas pues tenías que tener unos planes. Ahí todos los años cuando hay unas lluvias muy fuertes se arrastra un montón de materiales de tierra adentro que se depositan en la zona de cultivo y eso está dando una mortalidad muy alta y esos años son mortales, en especial en el periodo de crecimiento porque hay una mortalidad tremenda y desaparece.¿Y qué pasa? Qué hay unas protestas de ese sector, van a la Xunta y ésta lo que hace es financiar a esa gente, darle subsidio. Ahora mismo el marisqueo es importantísimo".

33 Idem. 
Biólogo 2o: "El origen del marisqueo fue el de una actividad subsidiaria y lo vendían para los restaurantes, la almeja, pero ahora es una economía empresarial".

Biólogo $1^{\text {o: " }}$ "Esto del marisqueo funcionaría bien y sería interesante darles formación a la gente que estaba desde el principio en el marisqueo, hasta ahora que se va a seguir a nivel industrial un cultivo intensivo. Funcionaría si el recurso fuera a más, pero el recurso va a menos. Tienes que traer de otros países, importar o implantando otra almeja, por ejemplo la japonesa y esto que hace... pues ya se irán viendo los resultados. No igual no es, es más dura que... una carne dura de caray".

Biólogo 2o: "Eso indica que el autóctono es el que mejor adaptado. Está desapareciendo y eso... o que el nivel de producción que querían no lo van a alcanzar".

Biólogo 1": "Existen pocos recursos, existe un sector que tenemos que seguir manteniéndolo y que vamos a dar una valorización a mayores al producto y entonces ahí vienen... las denominaciones de origen, la gallega a la hora del mercado es un plus que se va a pagar, entonces tenemos menos recursos pero más valorado, entonces puedes" 34 .

"Como a de aquí non e para todos os bolsillos, entonces empezaron implantando esa ameixa aquí. As cofradías que xa empezaron a implantar como foron $\mathrm{O}$ Grove, Arcade e outras pois estaban facendo moitos gastos. Nos hai tres ou catro anos, temos unhas zonas fangosas, de lodo que non produce nada, entón pedimos permiso para metela en esas zonas fangosas e bueno, estaban dando un resultado moi bo. Precisamente é unha das especies que casi todo o ano se está dando; nos éramos reacias (...).Empezou a implantarse en nosas praias, entonces dices ti... porque claro as corrientes tráenas, trae as semillas, a traer as semillas empezou aparecer en nosas playas. Entón vámolos a votala en zonas que non son de producción da ameixa babosa, ni ameixa fina y entonces temos a producción dividida e ... ¿si se expande? Eh, eh... algunha si, algunha si, pero bueno, sin ter nos ningunha.... Producción hay producción, ¿sabes o que pasa? Que daquela en catro ou cinco días quitabas toda a cantidad y ahora vas quitando o que che manda o mercado. No hay sobreexplotación,

${ }^{34}$ Entrevista a biólogos que relatan su experiencia en el sector del marisqueo. Cangas, Pontevedra. Diciembre del 2007. 
no, no, o que che manda o mercado. Si o mercado necesita mil kilos, quitas mil kilos, si necesita dez, dez. ¿Porque vas a traer tres mil kilos? “35

Esta realidad, contrastada por distintos agentes, sobre la trayectoria en el marisqueo a pie, nos lleva a cuestionar algunos de los planteamientos del proceso modernizador, mientras que se observa el modo en que diferentes focos de poder incursionan en el tejido social. Es decir, el recorrido proseguido por éstas en el seno de una feminizada profesión y la autoconciencia de una actividad mejor valorada, así como la autonomía alcanzada por su colectivo, socialmente depreciado, se encuentra, aún hoy día, en continua afrenta con el capitalismo patriarcal:

"Antes íase sábados, domingos y tal. Eu fun a Consellería de Pesca a decir: ¡vamos a ver, sábados y domingos, nos traballar! Todos aquí marchan de 'chiquita' a tomar viños e nos veña a limpiar. Nos temos que ter nosas horas o nosos días libres como teñen eles. Pero había mulleres que no querían... quixeran seguir indo sábados e domingos. Temos ahora duchas e os baños, temos ahora unha caseta alí para cambiarnos, botas e todo. Foi difícil poñelo pero púxonos o anterior gobierno y eu tíñale tanto medo porque considerábalo un partido cerrado y ahora co cambio, ¿no debería de ser al revés? Eu digo a esos... porque claro cando estas en un sitio donde estou eu, representando a un colectivo, cando a nivel local hai eleccións, veñen a buscarte todos os partidos, que importa que sea de dereitas ou de esquerdas o que queren e recoller os votos (...). Porque un profesor de la Universidad de Vigo hizo un libro 'A despensa de Area' ${ }^{36}$ habla de las mariscadoras de Moaña y tal y di que bueno que non considera que vaya a ter futuro" 37

El reconocimiento social y económico de esta actividad retroalimenta la autoestima de las trabajadoras, cuya identidad se ve fortalecida en base a estas faenas estrechamente vinculadas con la explotación y la protección de este recurso, actualmente muy revalorizado y de gran interés monetario. En conclusión, podemos sostener que en las faenas de las riberas, además de los distintos intereses que se entrecruzan en su trayectoria, se despliega una nueva relación con el medio natural. En dicho ecosistema se observan las habilidades y conocimientos adquiridos por saber

35 Mujer, 60 años. Moaña, Pontevedra. Diciembre del 2007.

36 SEQUEIROS, José Luis (dir.), A despensa, 1995.

37 Mujer, 60 años. Moaña, Pontevedra. Diciembre del 2007. 
vernáculo desplazado hasta lograr la domesticación de una parcela del mar que se ha renovado debido a los diferentes intereses, en continua confrontación, sobre un mismo territorio. En nuestro trabajo de campo registramos parte de la labor realizada por las nuevas profesionales después de crear en el 2002 la "Asociación de profesionales del marisqueo a pie de Galicia" (AREAL). Nos encontramos con una nueva forma de concebir la faena del marisqueo, cuyo eje vertebrador es un mercado donde impera la ley del valor, dentro del cual toda mercancía está destinada a aportar valores de cambio conforme a la lógica del sistema en el que se inserta, obteniendo su materialización última un alto valor adicional que enfrenta a distintos agentes. Por otro lado, a través del ejemplo etnográfico expuesto comprobamos como la segregación sexual continúa presente, mostrando la trayectoria de un trabajo feminizado donde no existiría a su vez una separación tajante entre trabajo y vida cotidiana. En dicho contexto se hacen evidentes determinadas contradicciones, materializadas en determinados perfiles y categorías estigmatizadoras, que llevarían a definir esta actividad femenina como "subalterna". De este modo hemos presentado un territorio cultivado por relaciones de privilegio y dominio de ahí que no estuvieran exentas de conflictividad social.

\section{LA APORTACIÓN DEL ECOFEMINISMO AL TRABAJO FEMINIZADO DE LAS RIBERAS MARÍTIMAS}

En este último apartado queremos mostrar como se conjuga la perspectiva ecofeminista dentro del territorio de frontera que son las riberas marítimas. La corriente ecofeminista de los últimos años cuestiona la tríada mujer/naturaleza/armonía frente a hombre/cultura/destrucción. Esta teoría ha sido criticada de universalista y esencialista, sin embargo el ecofeminismo deconstruye las dicotomías etnocentristas que contrapone la cultura a la naturaleza. Por ello pretende recuperar un pensamiento armónico en el que la dualidad cultura/naturaleza se integren. A partir de la filosofía ecofeminista hemos reconocido los cimientos de las estructuras de poder y la recuperación de una relación menos destructiva entre la naturaleza y la cultura. Ahora bien, dentro del ecofeminismo hay una corriente próxima al feminismo radical, reconocida en un ecofeminismo de afinidad, que definen a los hombres como seres destructivos y agresivos; en oposición a las mujeres como seres constructivos y pacíficos, autenticas madre-nutricias, con ello se pretende construir una ideología sobre un mítico matriarcado sobre el que no estamos de acuerdo. Pero también desde el ecofeminismo existe otra corriente que podríamos denominar materialista/socialista que intenta aunar lo social con lo natural de forma más dia- 
léctica. El ejemplo etnografico expuesto se ha basado, entre otros, en los planteamientos teórico-prácticos del ecofeminismo materialista, donde hemos considerado relevante incorporar a la praxis sus categorías de inmanencia y trascendencia, y con ello su proyecto político basado en el rechazo de la trascendencia y en la aceptación a cambio de la inmanencia, propia de las sociedades humanas. Esto supone el enfrentarse con las relaciones sociales jerárquicas y de asimetría en las cuales se sustenta la trascendencia, que es aquello que directamente crea patrones de explotación, opresión y degradación. Por el contrario, queremos resaltar que la inmanencia contiene una mayor responsabilidad política, por las consecuencias sociales y ecológicas de la existencia corporal. Si dichos conceptos expuestos son medidos en términos de relaciones sexo/género esto supone aceptar la naturaleza corporal de la vida humana, para que de este modo las relaciones (sexo/género) se perciban de otra manera, como una interacción entrelazada en el marco de las relaciones humanidad-naturaleza ${ }^{38}$ :

"Pero o que pasa e que é un mundo muy machista, lo que pasa es que ahí nos sabemos imponer a nosa... porque esa xente non quiso estar con mulleres y fixeron eles unha cooperativa. Manuel Rivas es un gran periodista gallego que escribe muito do mar y vino a facer aquí un reportaje y xa quitou en ese momento... que mirara un gran... ique as mariscadoras podían vivir! Xa mirou en nos esa unión, de cando baixa un periodista o calquer persoa a preguntar, recollen a esa persoa y explícanlle. Y alí acompañar, porque nos estamos tan unidas porque si estou falando contigo y non recollo o cupo as demais me axudan. Pues él todo iso mirou" 39

También consideramos oportuno incorporar en nuestra práctica empírica los planteamientos del análisis materialista sobre las estructuras políticas, sociales, culturales y económicas opresivas, al tratar de comprender la posición de los sujetos en cuanto a seres sexuados y su interacción socio-histórica con el medio, lo que significa un intento por ir más allá de la sustitución del sexo por el género. En dicho sentido, retomamos el interés de la corriente ecofeminista en el compromiso y obligatoriedad de las personas, inmersas en las culturas industriales modernas, por la regeneración y la reintegración de la cultura con el medio natural. Al respecto es elocuente el siguiente testimonio:

38 Véase MELLOR, Mary, Ecofeminismo, Siglo XXI, México, 2000, pp. 232-35.

39 Mujer, 62 años. Moaña, Pontevedra. Diciembre del 2007. 
"Nos, en un mundo como o marisqueo a pé donde o noventa por ciento son mulleres, en noso caso temos un home sólo, hai o marisqueo a pe y a flote, pero prácticamente en toda Galicia casi todas son mulleres. O que non e lóxico es que estemos gobernadas por un home en la Cofradía. En este momento somos douscentas vintetrés pero no momento que eu empecei, cando eu entrei eran mil setenta en Moaña y ahora un home pero de aquela había muitos. O que pasaba que de aquela daban unha licencia de mariscador, era o carné de mariscador que no tiña mais que cumplir unha norma que era ser español y mayor de dieciséis anos, en este momento non pasa iso pero para que non pase iso luchouse muitísimo. Nos, as mulleres, queríamos en noso carné de identidad... ponían en noso carnet... 'labores'. Eu non quería que en mi carné de identidad pusieran 'labores' porque eu era mariscadora, quería luchar por o meu oficio que era o que me gustaba. Pero quiero decir que hace oito anos cambiamos de fío, hai oito anos que vinieron esos señores lo que era a Xunta General da Cofradía, mulleres non. Si querías ser mariscadora pues... bueno, ahora serían gobernadas por eles y eu digo pero bueno e ¿por qué? Porque estamos facendo a Xunta General que a partir de ahí se decide y digo yo ¿por qué? Porque as mulleres non entendedes o volumen de negocios nin poder adquisitivo. Vale, os mariñeiros teñen mais volumen de negocios y mais poder adquisitivo pero a Cofradía esta composta por socios y socias" 40

A través de una perspectiva ecofeminista podemos corroborar como las mujeres entrevistadas están oprimidas, especialmente en el seno de sus relaciones sexuales y familiares, tal como hemos podido comprobar durante el trabajo de campo, dentro del marco más amplio de las sociedades y culturas marítimas de las que forman parte. Sobre esto último, además de lo mencionado con respecto a las políticas de las cofradías, también da fe el siguiente relato:

"Si elas queren facer de comer ¡ay... téñome que marchar que me ven o meu home para a comida y tal! ¡Ála! y eu deciálle, porque logo todas nos conocemos: esto es antes... o traballo y como tal tes que decirlle o teu home, isto e o teu, isto e o meu, o primeiro que chegue a casa e o primeiro que pon a sartén' ¿Vale? Eso e o primero que temos que... bueno. Xa hoxe como se vai tendo outra mentalidad distinta, distinta, pues... Mentras tanto

40 Idem. 
como xa temos un horario, tanto na entrada como na salida que pode variar uns minutos de unhas a outras, xa están. ¿Vai a tardar muito María o Carmen? ¡Non, está terminando, porque o grupo de la faltalle un pouco, termina en dez minutos! y... subimos todas para arriba. Entón, xa hasta esa cousa que con o marido, xa hoxe, ten con ela xa... é outra cousa. Queiras ou non queiras xa hay unha independencia económica que non e muita pero... A o ano es un millón o millón y pico, pero tamén son por esas horas que traballamos, porque tes dous o tres horas de traballo y el resto xa o tes para a casa e de luns para jueves y si fora un jueves como hoxe que xa non fomos... y o mellor chega un mes de navidad y quitas pois o mellor, que fomos poucos días os de navidad, uns once días e quitamos a dos mil y pico de euros, non e muito pero son dos mil y pico de euros. Ahora fuimos estos tres días y temos catrocentos coarenta euros ganados, non e muito ganado pero sí es más digno"41

Desde el ecofeminismo-socialista se ha puesto un mayor interés teórico-metodológico en la posición ocupada por las mujeres y los hombres en las relaciones humanidad-naturaleza, que en definitiva es el contexto en el que se desarrolla esta investigación. En consecuencia la posición defendida desde esta óptica es la de un realismo inmanente, como punto de partida del conocimiento ${ }^{42}$, donde la biodiversidad y la diversidad cultural mantengan una relación más dinámica y no maniquea respecto al antagonismo entre humanidad y naturaleza. Desde esta perspectiva, aplicada a los estudios de casos como el presente, se adquiere una visión holística de la humanidad como parte de la naturaleza, ya que ésta no puede existir sin aquella. O sea una naturaleza que forma parte de la condición humana, donde el ampliado y polisémico concepto de corporeidad es reconstruido a partir del cuestionamiento de los fundamentos de un pensamiento ilustrado y patriarcal, que excluye y oprime áreas de la vida humana en nombre de un determinismo biológico. Es decir, confronta la posición de las mujeres en la dualidad de naturaleza/cultura y el constructo de una ide-

41 Mujer, 60 años. Moaña, Pontevedra, diciembre del 2007.

42 Aceptar la "inmanencia de la humanidad" supone que el conocimiento sobre el mundo natural implica en consecuencia un conocimiento parcial. En la cultura y en el entorno marítimo el conocimiento se adquiere por distintas vías, lo cual en relación al término barajado conlleva que hay diferentes modos de realizar esta inmanencia: mediante la comprensión científica, pero también a través del conocimiento local de las personas que se "en-frentan" corporal y diariamente con las fuerzas naturales del espacio que estamos analizando. Esta experiencia corpórea (psicofísica), en dicho medio, es un canal distinto de percepción y conocimiento. Sobre esta reflexión teórica aplicada a nuestra práctica empírica, véase MELLOR, Mary, Ecofeminismo, p. 230. 
ología excluyente del patriarcado capitalista opresor que permanece preocupada por librarse de las ataduras de la corporeidad y del tiempo biológico. Un enfoque que nos orienta para un debate político ante las privilegiadas experiencias de las informantes y su aportación desde la intrahistoria, cuyo principal testimonio sintetizó la histórica relación entre ambas dimensiones en los siguientes términos:

"Miña nai me decía: <O mar es femia y sempre está parindo...> 43 .

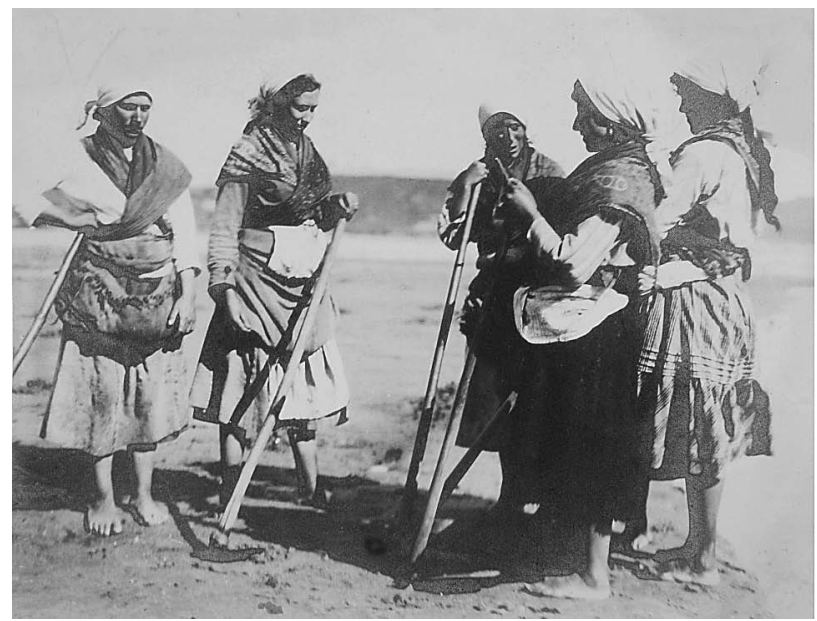

“Mariscadoras” (Anónimo). Archivo del Museo de Pontevedra R.3974- Sig. 7.7.1

\section{BIBLIOGRAFÍA}

ALBERT, Jean Pierre: "Lo que dice la palabra (y que a menudo se pierde) en Historia, Antropología y Fuentes Orales, Barcelona, $\mathrm{n}^{\circ}$ 30, 2003, pp. 65-81.

AMORÓS, Celia: "Notas para una teoría nominalista del patriarcado". Asparkía. Investigació feminista, $\mathrm{n}^{\circ}$ 1, Castellón, Publicacions de la Universitat Jaume I, 1992.

BEIRÁS, Xosé Ramón, (dir.): Posibilidades y limitaciones económico ecológicas del polo de desarrollo de Vilagarcía de Arousa: estudio del sector marisqueo en la Ría de Arousa, 1976

BROULLÓN ACUÑA, Esmeralda: "Mujer y deseo en las sociedades culturalmente construidas", en $\mathrm{M}^{\mathrm{a}}$ José de la Pascua, $\mathrm{M}^{\mathrm{a}}$ del Rosario García-Doncel, Gloria Espigado (eds.), Mujer y Deseo. Servicio de Publicaciones de la Universidad de Cádiz e Instituto Andaluz de la Mujer. Consejería de la Presidencia, Junta de Andalucía, 2005.

${ }^{43}$ Mujer, 60 años. Moaña. Pontevedra, diciembre del 2007. 
_, El Estado y la discriminación de género. Un estudio empírico: $<$ Rosa dos Ventos $>$, Trocadero, $\mathrm{n}^{\circ}$ 18, Universidad de Cádiz, 2006.

- "A inmigración galega no suratlántico peninsular. A construción social da identidade a través de testemoños orais", (Traducción de Fernández Rei, Francisco) Trabe de ouro, nº 69, Santiago de Compostela, Sotelo Blanco, 2007.

GAGO CONDE, Constantino y ARDORA FORMACIÓN: "La mujer en la pesca en Galicia", presentación de la investigación realizada para la Xunta de Galicia en el Simposio, La mujer en la pesca, la acuicultura y el marisqueo en el contexto comunitario, 4-6 de febrero, Xunta de Galicia, Universidad de La laguna y Red Europea FEMMES, 2004.

ENGELS, Friedrich: Origen de la familia, la propiedad privada y el Estado, Madrid, Fundamentos, 1987.

HARTMAN, Heidi: "Capitalism, Patriarchy and Job Segregation by Sex" en, Z.R. Eisenstein, Capitalism, Patriarchy and the case form socialist feminism, London, Monthly Review Press, 1979 (Publicado originalmente como suplemento de Sings, 1 (3), 1976, parte 2)

JÓNNASDÓTTIR, Anna: El poder del amor: ¿Le importa el sexo a la democracia? Madrid, Feminismos/ Cátedra, 1993.

MARINAS, José Manuel y SANTAMARÍA, Cristina: La Historia Oral: Métodos y Experiencias, Debate, Madrid, 1993.

MARUGÁN PINTOS, Begoña: Y colleron ese tren. Profesionalización de las mariscadoras gallegas, Consellería de Pesca y Asuntos Marítimos, Xunta de Galicia, 2004.

MEILLASOUX, Claude, Mujeres, graneros y capital, México, Siglo XXI,.

MELLOR, Mary: Feminismo y Ecología, México, Siglo XXI , 2000.

MIES, Maria: Patriarchy and accumulation on a world scale, London, Zed Press, 1986 _, Radical ecology, London, Routledge, 1992.

MOORE, Henrietta: Antropología y feminismo, Madrid, Feminismos/Cátedra, 1991.

PARDELLAS DE BLAS, Xulio: "El trabajo de la mujer en la pesca y el marisqueo en Galicia", en VV. VV.: Jornadas sobre economía y sociología de las comunidades pesqueras, MAPA y la Universidad de Santiago de Compostela, 1989, pp. 431- 452.

_, "Estrategias familiares de Marisqueo y la Pesca artesanal en Galicia", ERES, Serie Antropología, 1990, vol.2: 115-126.

PULEO, Alicia:"Ecofeminismo: hacia una reflexión filosófico-política de 'naturaleza’ y ‘ser humano', en Amorós, C., Feminismo y filosofía, Síntesis, Madrid, 2000.

_, "Feminismo y ecología", en Feminismo. es... y será, Jornadas Feministas, Córdoba, Servicio de Publicaciones Universidad de Córdoba, pp. 227-234, 2001.

RUBIN, Gayle: <The Traffic in Women: notes on the "political economy" of sex>, en R. Reiter (comp.), Toward and anthropology of women, Nueva York, Monthly Review Press, 1975, pp. 157210.

ROSALDO en, Olivia HERNES y Kate YOUNG (comp.), 1979, p. 155

SANTASMARINA RAPOSO, Prudencia: "La mujer mariscadora: donde la diferencia sí es desigualdad", en La mujer: clave del desarrollo rural, Junta de Andalucía, Sevilla, 1997. 
Anna SCOTT, Gender: A useful category of historical analysis", American Historical Review 91 (5), 1986, pp. 1053-1075. ("El género: una categoría útil de análisis histórico”, en Alemang, J.S. y Nash, M., Historia y Género: Las mujeres en la Europa moderna y contemporánea, Valencia, Alfons el Magnànin, 1990).

SEQUEIROS, José Luis: A despensa de area, Vigo, Xerais, 1995.

SEQUEIROS, José Luis: (dir.) A despensa de area, Xerais, Vigo, 1995

STANLEY, Liz: The Auto/Biographical I: Theory and Practice of Feminist Auto/Biography, Manchester, Manchester University Press, 1992.

THOMSON, Paul: "Women in the Fishing: The Roots of Power between the Sexes" en Society for Comparative Study of Society and History, pp. 3-31, 1985. ("Espacio y poder entre los hombres y mujeres de las comunidades marítimas". en Vilanova (ed.) El poder en la sociedad, Barcelona, Bosh, 1986, pp.23-33).

YOUNG, Iris: "Socialist feminism and the limits of dual system theory", Socialist Review, $\mathrm{n}^{\circ}$ 50-51, vol.10, 1980, pp. 169-188. 